\title{
Rancang Bangun Sistem Informasi Pembelian Barang Percetakan CV. AKA Bekasi
}

\author{
Hesti Rian $^{* 1)}$, Septiyono Mugi Harjanto ${ }^{2)}$ \\ ${ }^{12)}$ Program Studi Manajemen Informatika, Politeknik LP3I Jakarta \\ ${ }^{*}$ Correspondence author: hestiriangustiawan@gmail.com, DKI Jakarta, Indonesia
}

\begin{abstract}
Abstrak
Penelitian membahas studi kasus Rancang Bangun Sistem Informasi Pembelian Barang Percetakan CV. AKA Bekasi. CV. AKA sendiri merupakan perusahaan yang bergerak dibidang Digital Printing, dimana kegiatan sehari - harinya menerima pesanan dan orderan printing dari pihak customer. Peelitian dilakukan langsung di percetakan CV. AKA untuk menemukan kendala yang ada. Teknik pengumpulan data dilakukan dengan 2 cara yakni dengan cara observasi dan wawancara. Berdasarkan hasil observasi dan wawancara ditemukan beberapa permasalahan. Permasalahan adalah banyak pesanan dan orderan dari customer membuat CV. AKA selalu memesan barang kepada supplier untuk memenuhi stok-stok kebutuhan yang kosong dengan cepat. Tetapi karena masih menggunakan pencatatan dengan buku, pemesanan secara manual membuat CV. AKA terlambat untuk mengisi stok-stok kebutuhan yang kosong. Masalah yang ditimbulkan dalam sistem berjalan tersebut adalah kurang maksimalnya pendataan data pemesanan dan terlalu banyak berkas yang belum rapih sehingga menghambat pembuatan laporan. Penelitian mengembangkan sistem informasi yang mudah di operasikan. Penyimpanan data menjadi lebih tertata rapih dengan menggunakan sistem informasi berbasis web.
\end{abstract}

Kata Kunci: Rancang Bangun, Sistem Informasi, Pembelian, Stok, Web

\begin{abstract}
The study discusses a case study of a Design of Information Systems for Purchasing Printing Goods CV. AKA Bekasi. CV. AKA itself is a company engaged in Digital Printing, where its daily activities accept orders and printing orders from the customer. The research was conducted directly at the printing press CV. AKA to find obstacles that exist. Data collection techniques are done in 2 ways namely by observation and interview. Based on observations and interviews found several problems. The problem is that many orders and orders from customers make a CV. AKA always orders goods to suppliers to fill empty stock needs quickly. But because it still uses bookkeeping, ordering manually makes a CV. AKA is too late to fill up the empty stock. The problems that arise in the current system are the inadequate data collection of ordering data and too many files that have not been neat, thus hampering report generation. Research develops information systems that are easy to operate. Data storage becomes more organized by using a web-based information system.
\end{abstract}

Keywords: Design, Information Systems, Purchasing, Stock, Web

\section{PENDAHULUAN}

Di dunia bisnis kepuasan pelanggan sangat penting, sehingga banyak cara yang sering di tempuh untuk memperbaiki sistem di sebuah perusahaan. Seiring dengan berkembangnya teknologi yang sangat pesat banyak perusahaan yang menggunakan atau memanfaatkan teknologi dalam memperbaiki sistem di perusahaan tersebut.

Jika diperhatikan secara mendalam maka akan terlihat jelas bahwa permasalahan adalah terletak pada penggunaan data dan informasi yang kurang akurat. Penerapan suatu sistem data dan informasi sebenarnya tidak terlepas dari penggunaan peralatan elektronik yang dapat membantu manusia dalam proses penanganan sistem informasi. 
Rumusan masalah dalam penelitian ini adalah bagaimana proses pembelian barang percetakan pada CV. AKA, adakah kendala pada proses pembelian barang percetakan dan bagaimana solusi pemecahan masalah terhadap kendala tersebut.

Berdasarkan rumusan masalah di atas, maka tujuan penelitian ini adalah untuk mengetahui proses dan kendala pembelian barang percetakan pada CV. AKA serta menemukan pemecahan masalah terhadap kendala tersebut. Penelitian juga bertujuan meningkatkan keakuratan di dalam proses jasa percetakan dengan mempergunakan suatu sistem yang berbasis database. Dengan adanya sistem yang berbasis database ini, proses jasa akan menjadi lebih mudah dan lebih tepat waktu sesuai dengan yang di harapkan oleh pemakai atau user.

\section{METODE}

Penelitian ini dilaksanakan pada bulan Februari 2019 dengan menggunakan metode observasi dan wawancara pada CV. AKA, menganalisa, merancang dan pembangunan sistem informasi pembelian barang percetakan sampai bulan November 2019.

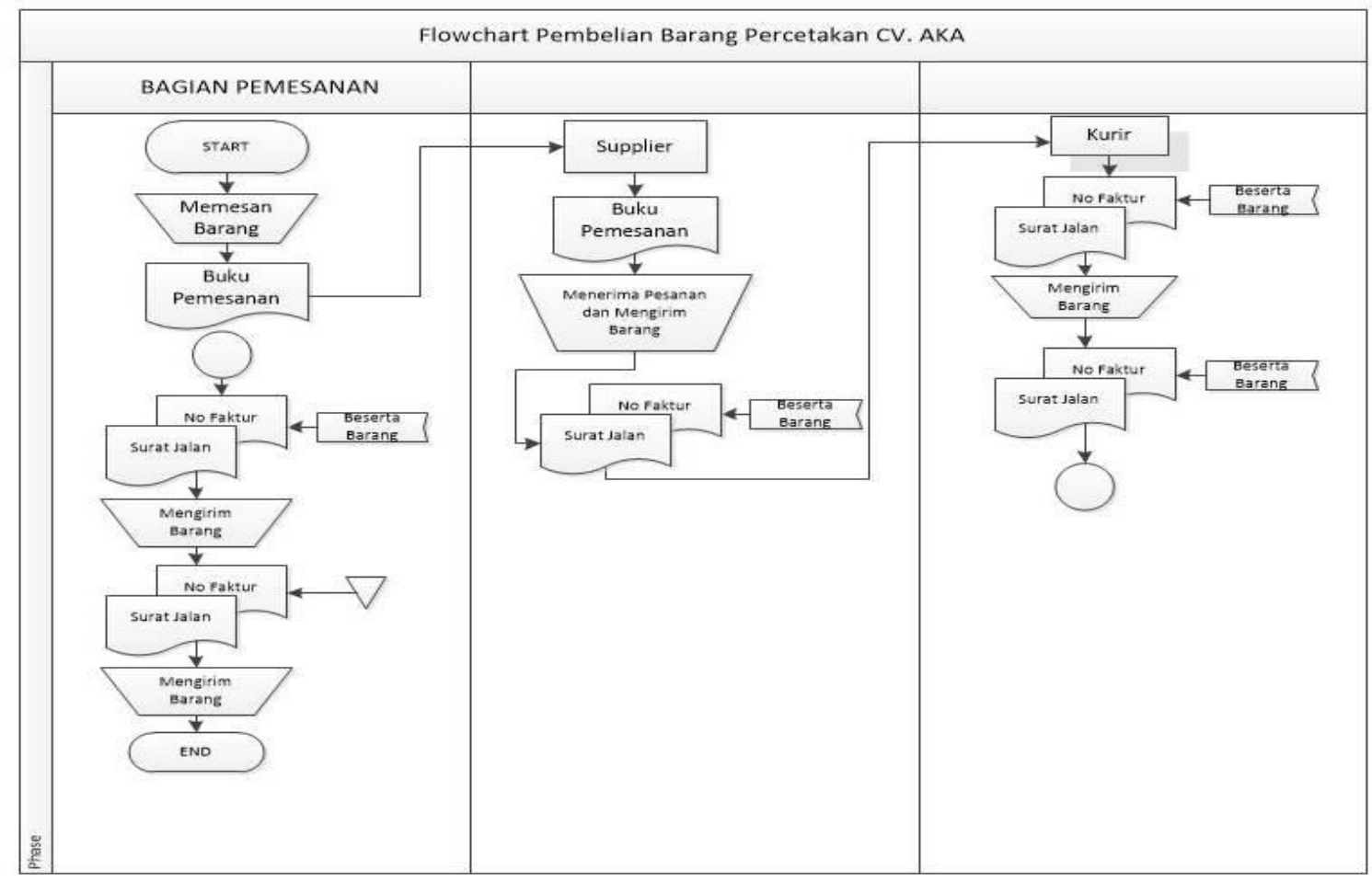

Gambar 1. Flowchart Alir Dokumen Sistem Berjalan 


\section{HASIL DAN PEMBAHASAN}

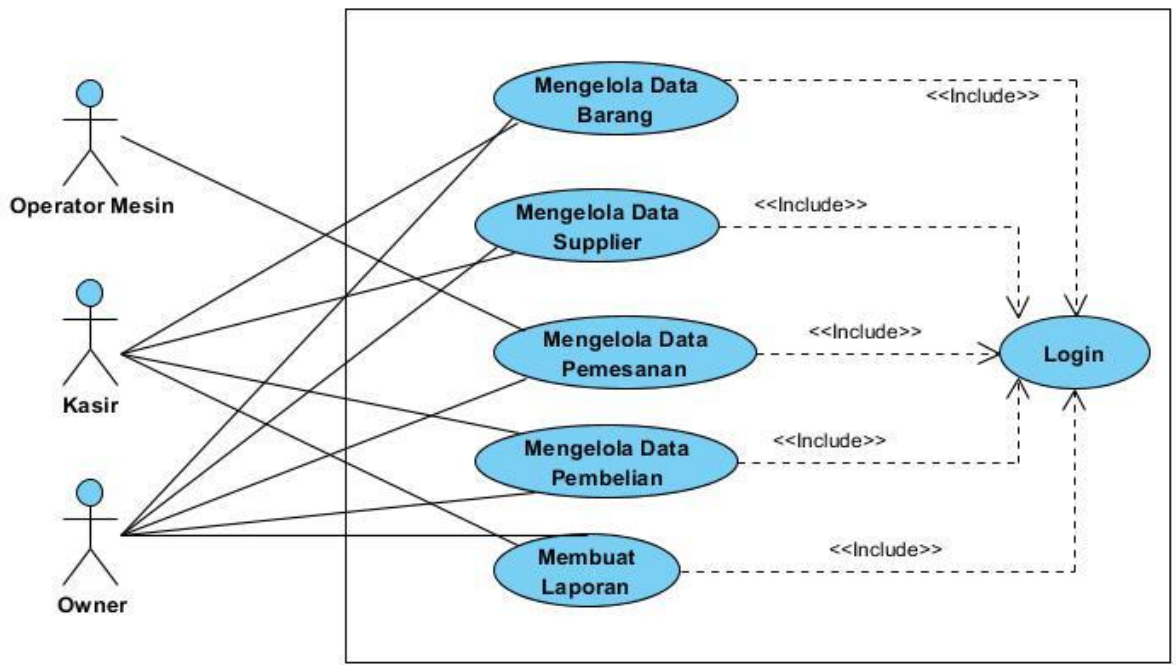

Gambar 2. Use Case Diagram

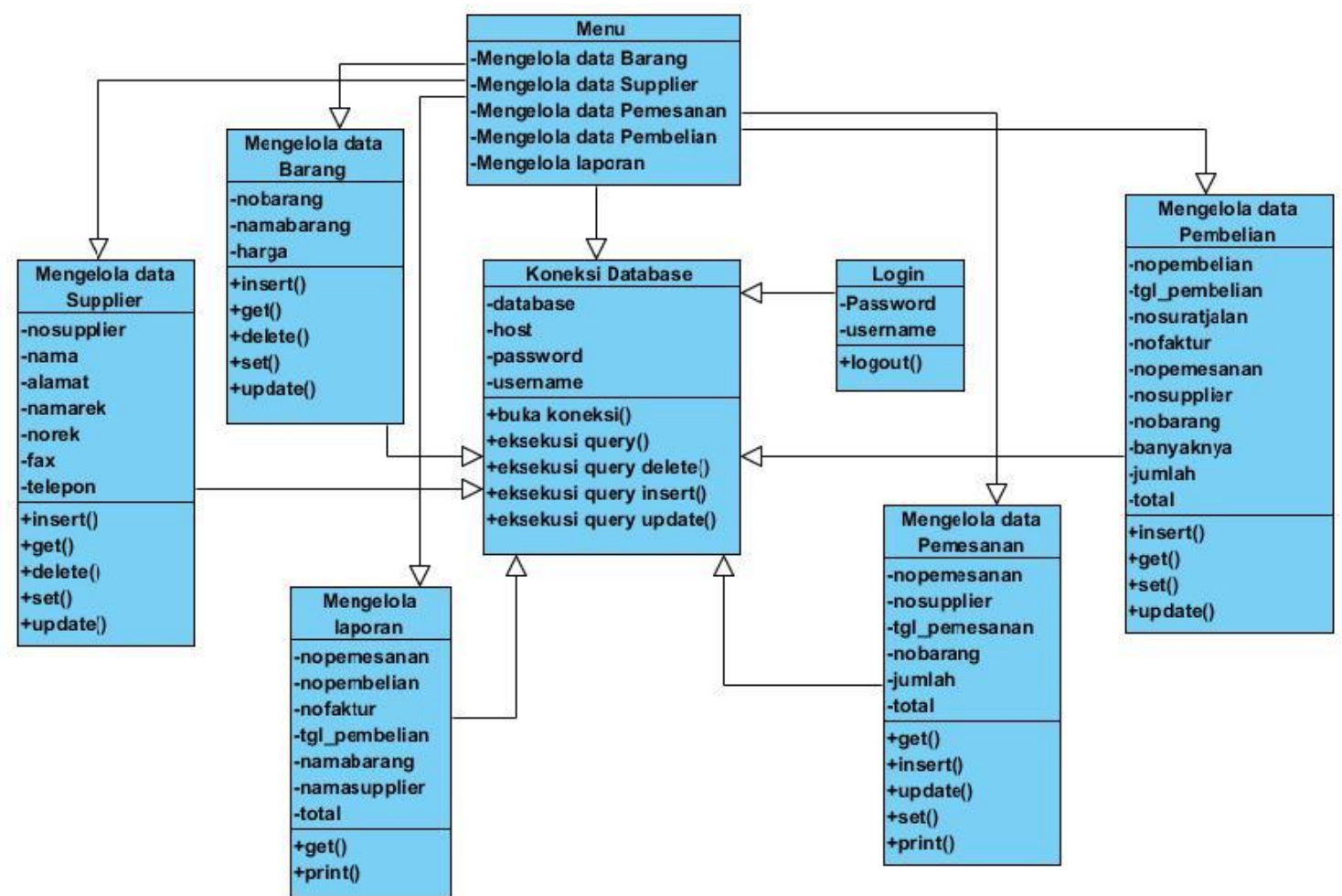

Gambar 3. Class Diagram 


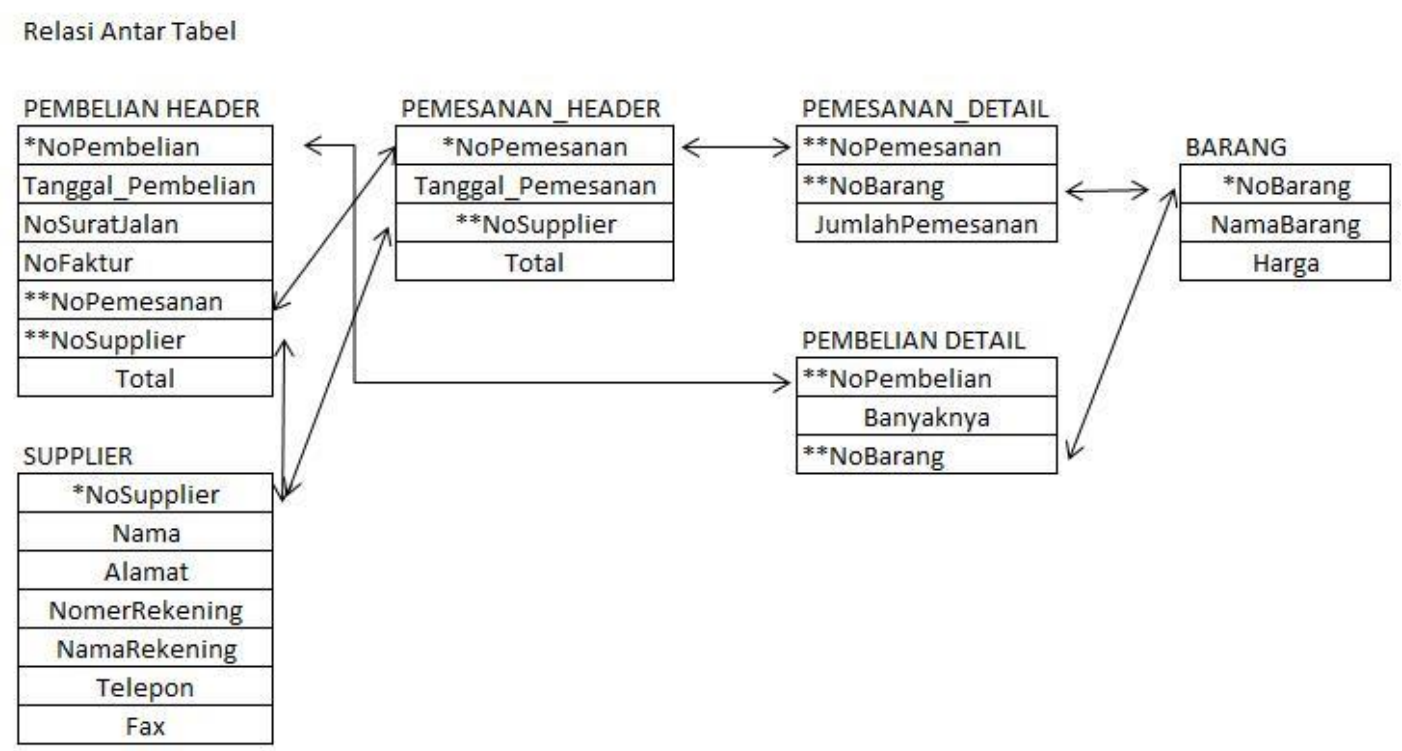

Gambar 4. Relasi Antar Tabel

\section{Kebutuhan Infrastruktur}

Adapun perangkat yang dibutuhkan adalah :

\section{Sistem Operasi}

Windows 7 Ultimate 32Bit / 64Bit

Text Editor : Notepad ++

Web Server : XAMPP

2. Kebutuhan Hardware

Prosesor Intel ${ }^{\circledR}$ Core ${ }^{\mathrm{TM}} 2$ Duo E7400

RAM 2 GB

Mouse

Keyboard

Monitor

3. Kebutuhan Device

Printer

\section{KESIMPULAN DAN REKOMENDASI}

Sistem informasi yang dikembangkan dapat dioperasikan dengan mudah. Penyimpanan data lebih tertata rapih dan terperinci dengan mengunakan sistem berbasis web. Proses pembelian barang untuk kebutuhan percetakan menjadi lebih cepat dan tepat, sesuai dengan kebutuhan proses produksi.

Direkomendasikan untuk memperluas lingkup sistem informasi, misalnya dengan menambahkan proses pembelian, proses pembuatan laporan keuangan, dan lain-lain. 


\section{REFERENSI}

AS Rosa, M. S. (2014). Rekayasa Perangkat Lunak. Bandung: Informatika.

Fathansyah. (2018). Basis Data. Bandung: Informatika.

Kadir, A. (2016). Pemrograman Database MySQL untuk pemula. Yogyakarta: MediaKom.

Kotler, P. (2018). Manajemen Pemasaran. Jakarta: PT. Indeks.

Pratama, I. P. (2016). Integrasi dan Migrasi Sistem. Bandung: Informatika.

Saputra, A. (2018). Project PHP : Menyelesaikan Website 30 Juta Secara Profesional. Cirebon: CV. ASFA Solution.

Suprapto, F. (2018). Rekayasa Perangkat Lunak. Bandung: Lentera Ilmu Cendekia. 